\title{
O VERBETE DA MORFOLOGIA NOS DICIONÁRIOS DE LINGUÍSTICA E GRAMÁTICA
}

\author{
THE MORPHOLOGY ENTRY IN THE DICTIONARIES OF LINGUISTICS AND \\ GRAMMAR
}

\author{
José Pereira DA SILVA \\ UERJ \\ pereira@filologia.org.br
}

\begin{abstract}
Resumo: Apesar do progresso recente da terminologia em diversas especialidades nas diversas áreas de conhecimento, tem sido bastante reduzida a produção lexicográfica relativamente à terminologia linguística e gramatical, principalmente em língua portuguesa, incluindo nesta carência as boas traduções que poderiam compensá-la. Para sanar em parte essa deficiência em nossa terminologia linguístico-gramatical, está em desenvolvimento o projeto do Dicionário Linguístico-gramatical da Língua Portuguesa, de cujo corpus atualmente recolhido foi preparado o material que aqui se disponibiliza, consistente da coleta de dados registrados em dicionários de linguística e gramática disponíveis em nossa biblioteca particular: Cândido de Oliveira, Celso Pedro Luft, David Crystal, Jean Dubois et alii, Joaquim Matoso Câmara Júnior, Sílvio Edmundo Elia, Tassilo Orpheu Sapalding, Walmirio de Macedo. Naturalmente, a obra incluirá a atualização baseada nas principais gramáticas atualmente recomendadas, como as de Ataliba T. de Castilho, Celso Cunha e Lindley Cintra, Evanildo Bechara, José Carlos de Azeredo, Rocha Lima, Mário Alberto Perini, Mário Vilela e Ingedore Villaça Koch, Maria Helena de Moura Neves, Marcos Bagno, Napoleão Mendes de Almeida e em outros dicionários. Neste artigo, pretende-se alertar para a variedade de enfoques possíveis na definição de termos linguísticos e gramaticais, considerando principalmente os termos mais comuns e de conhecimento aparentemente de domínio geral, apesar de surpreender até mesmo os especialistas, quando se observam os diferentes pontos de vista pelos quais se pode ver cada um desses termos. Apesar de ser importante, as considerações históricas ou diacrônicas não serão consideradas aqui. Nas considerações finais, incluiremos uma breve lista de termos relativos à morfologia, os quais serão incluídos no referido dicionário.
\end{abstract}

Palavras-chave: Morfologia. Morfossintaxe. Flexão. Formação de palavras.

Abstract: In spite of the recent progress of terminology in several specialties in the different areas of knowledge, lexicographical production has been greatly reduced in terms of linguistic and grammatical terminology, especially in Portuguese. Included in this lack of good translations which could compensate for it. In order to solve this problem in part in our linguistic-grammatical terminology, the project of the Linguistic-Grammatical Dictionary of the 
Portuguese Language is being developed. From the corpus currently collected from this dictionary was prepared the material that is available here. Such a corpus consists of collecting data recorded in linguistics and grammar dictionaries available in our private library: Cândido de Oliveira, Celso Pedro Luft, David Crystal, Jean Dubois et alii, Joaquim Matoso Câmara Júnior, Sílvio Edmundo Elia, Tassilo Orpheu Sapalding, Walmirio de Macedo. Naturally, the work will include the update based on the currently recommended grammars such as Ataliba T. de Castilho, Celso Cunha and Lindley Cintra, Evanildo Bechara, José Carlos de Azeredo, Rocha Lima, Mário Alberto Perini, Mário Vilela And Ingedore Villaça Koch, Maria Helena de Moura Neves, Marcos Bagno, Napoleão Mendes de Almeida and in other dictionaries. In this article, the aim is to alert to the variety of possible approaches in the definition of linguistic and grammatical terms. We consider, above all, the most common terms and those of general domain knowledge, even though it is surprising even to the experts, when one observes the different points of view by which each of these terms can be seen. In the final considerations, we will include a brief list of terms related to morphology which will be included in this dictionary.

Keywords: Morphology. Morfossintaxe. Inflexion. Word formation.

\section{Considerações iniciais}

Apesar de haver entre nós um bom número de gramáticas e de estudos gramaticais produzidos ou reeditados recentemente, observa-se a carência de um bom dicionário terminológico de linguística e gramática, seja em sentido amplo, seja aplicado especialmente à língua portuguesa.

A partir dessa constatação, está sendo preparado o Dicionário de Linguística e Gramática, de cujo material até o momento recolhido, será apresentado este artigo sobre o verbete morfologia, relacionado em nove dicionários já consultados (vide Referências).

Serão apresentados os tópicos mais recorrentes no referido verbete, concluindo-se com uma relação meramente nominal de verbetes que constarão no Dicionário suprarreferido, para futuras e mais completas pesquisas, fixandose a atenção nas informações sincrônicas e reduzindo-se ao mínimo as comparações com outras línguas modernas.

\section{O verbete morfologia e suas remissões}

Nem todos os dicionários de linguística e/ou de gramática têm o verbete "morfologia" desenvolvido in loco, como ocorre, por exemplo, com o Dicionário 
de Matoso Câmara, que, simplesmente, remete o consulente para os verbetes Gramática, Morfema, Distribuição e Pronome.

Não se trata, necessariamente, de se valorizar mais ou menos o verbete, mas de uma questão metodológica de disponibilização dos verbetes.

Aqui, por exemplo, em que não se pretende apresentar todo o desenvolvimento do verbete nos diversos dicionários, escolhemos alguns dos verbetes internamente aludidos, para apresentação explícita dos conteúdos, visto que seria impossível disponibilizar todos os subverbetes ou verbetes internos relativos à morfologia.

Entre os verbetes omitidos aqui, boa parte está relacionada na conclusão, apenas para dar uma ideia do que ainda se poderá consultar sobre o tema, considerando apenas o que é apresentado por alguns gramáticos atualmente em atividade e cujas gramáticas vêm sendo mais utilizadas na formação de professores da área de letras e na preparação de aulas e trabalhos acadêmicos.

\subsection{Morfologia}

Morfologia é o estudo da constituição das palavras e dos processos pelos quais são construídas a partir dos morfemas, e a parte da gramática que estuda as classes de palavras, sua estrutura e formação, assim como suas flexões.

Segundo Sílvio Edmundo Elia, no Dicionário Gramatical (1962, s.v.), morfologia é a parte da gramática que se ocupa com o aspecto formal das palavras, opondo-se à fonologia (que estuda os fonemas) e à sintaxe (que trata da frase).

Em outros termos, segundo Walmírio de Macedo, em seu Dicionário de Gramática (1979), morfologia é a parte da gramática que estuda a forma das palavras. Ou seja: a flexão, a composição, as variações léxicas e a determinação das diferentes categorias gramaticais. 
Resumindo, Walmírio de Macedo ensina que "A morfologia trata das diversas categorias de palavras e das diferentes formas de flexão e de suas classes". (MACEDO, 1979, s.v.)

Tassilo Orpheu Spalding, no Dicionário Brasileiro de Gramática (1971, S.v.) é mais explícito, ao ensinar que morfologia é o estudo das palavras quanto à sua estrutura, formação, flexão e classificação e que, portanto, trata: a) da estrutura das palavras (raiz, radical, tema, afixo etc.); b) da formação das palavras (derivação, composição e hibridismo); c) da flexão das palavras (gênero, número, voz, grau etc.) ${ }^{1}$; d) da classificação das palavras (substantivo, artigo, adjetivo, numeral, pronome, verbo, advérbio, preposição, conjunção e interjeição), lembrando que, para estudar bem este verbete, é necessário ver todos e cada um desses outros.

Para considerar a morfologia, no estudo gramatical, podemos fazer o que se denomina análise morfológica, que consiste em classificar a palavra, informar sua flexão, o processo de formação e os elementos mórficos que a constituem como demonstra Tassillo Orpheu Spalding (1971, p. 141): "apedrejamento" - substantivo comum, masculino, singular, abstrato, composto por prefixação, derivado por sufixação, formado simultaneamente por composição e derivação; prefixo: a-, radical: -pedr-, sufixo: -ej-, que indica repetição; vogal temática -a-, da primeira conjugação; sufixo nominal: -ment-; desinência: o (masculina singular). ${ }^{2}$

Celso Pedro Luft, no Dicionário Gramatical da Língua Portuguesa (1972, s.v.) diz que se distinguem duas definições de morfologia: a morfologia propriamente dita, que, em seu sentido restrito, trata do aspecto gramatical das palavras (flexões e classificações), e a morfologia impropriamente dita, que trata de problemas lexicais e do aspecto externo das palavras; ou seja, de sua origem, evolução, estrutura e formação, que também tem sido chamada de lexiologia ou lexicologia.

\footnotetext{
${ }^{1} \mathrm{Na}$ língua portuguesa, as categorias de voz e de grau não são expressas pelo processo de flexão, mas depor derivação, ao contrário do latim e de outras línguas.

${ }^{2}$ Poderíamos fazer a mesma análise a partir dos constituintes imediatos, assim como poderíamos tratar a desinência de masculino como vogal temática (considerando o gênero como categoria imanente no substantivo) e identificar a desinência zero, como marca de singular em oposição ao plural. Portanto, a morfologia não é um campo de paz e tranquilidade entre os linguistas e gramáticos.
} 
O termo "lexiologia", preferido por Manuel Said Ali (ALI, 1971) e José Oiticica, não tem curso internacional, motivo pelo qual se fixou como "morfologia", em nossa nomenclatura gramatical, que entende que a morfologia trata das palavras: a) quanto a sua estrutura e formação; b) quanto a suas flexões; c) quanto a sua classificação, apesar de não dar nome a cada uma dessas subdivisões.

As nomenclaturas mais correntes para as subdivisões da morfologia são os seguintes: a) mórfica - que trata da estrutura e formação das palavras; b) flexionismo - que trata das flexões; c) taxionomia - que trata de sua classificação.

Segundo Joaquim Matoso Câmara Júnior, no Dicionário de Filologia e Gramática [1968, s.v.], para estudar e entender a morfologia, é necessário ver os verbetes gramática, morfema, distribuição e pronome. Por questão de espaço, no entanto, não incluiremos todos esses verbetes neste artigo, apesar de não discordarmos do nosso primeiro grande linguista.

David Crystal, no Dicionário de Linguística e Fonética (1988, s.v.) mostra como a morfologia é vista pelos linguistas, considerando-a como parte da gramática que estuda a estrutura e as formas das palavras, principalmente por meio das construções com morfemas. Em geral, a morfologia trata da flexão e da formação das palavras. Tratando da análise das palavras em morfemas (análise morfêmica), faz-se um estudo sincrônico, mas a análise morfológica é uma expressão mais geral, que se aplica também aos estudos diacrônicos, podendo tomar diversas formas, dependendo da corrente linguística preferida.

Neste caso, pode-se dizer, sinteticamente, por exemplo, que

Na linguística gerativa, a morfologia e a sintaxe não são dois níveis separados; as regras sintáticas de uma gramática se aplicam à estrutura das palavras, assim como aos sintagmas e às sentenças; e as noções morfológicas emergem apenas no momento em que o resultado do componente sintático precisa receber uma representação fonológica (através das regras morfofonológicas). (CRYSTAL, 1988, s.v.)

Jean Dubois et alii, no Dicionário de Linguística (1998) também divergem em alguns detalhes, em relação ao conceito, classificação e divisão da morfologia, apesar de concordarem, na base, com os demais lexicógrafos 
citados. Para ele, a morfologia é o estudo das formas das palavras, em oposição ao estudo das funções, que é o campo da sintaxe.

Como a maioria dos autores, Jean Dubois et alii entendem que a morfologia também pode ser compreendida como a descrição das regras que regem a estrutura das palavras ou como a descrição das regras da estrutura interna das palavras e de combinação dos sintagmas em frases.

No primeiro caso, descreve as regras de combinação entre os morfemasraízes para constituir "palavras" (regras de formação de palavras) e as diferentes formas que elas tomam conforme a categoria de número, gênero, tempo, pessoa e, conforme o caso, opondo-se à sintaxe, que descreve as regras de combinação entre morfemas para constituir frases. Mas, no segundo caso, descrevendo as regras da estrutura interna e da combinação das palavras na frase, confunde-se com a formação de palavras, flexão e sintaxe, mas se opõe à lexicologia e à fonologia, donde a preferência pelo termo morfossintaxe como substituto do termo morfologia.

Ainda não trabalhamos todos os dicionários de linguística e filologia disponíveis, mas já no satisfazem as reflexões levantadas pelos autores até aqui consultados, de modo que passarmos a considerar, em ordem alfabética, alguns termos mais comuns nos estudos morfológicos para mostrar as contribuições que essas obras de referência terminológica oferecem.

\subsection{Adjetivo}

Adjetivo (do latim adjectivum, derivado de adjectu, supino de adjicio, composto de ad + jacio, e significa apenas "lançado ao lado de, justaposto") é a palavra modificadora do substantivo, que se junta ao nome para expressar uma qualidade que Ihe seja inerente ou que Ihe é atribuída. Assim, em homem gordo, mulher elegante, gordo e elegante são adjetivos.

$\mathrm{O}$ adjetivo pode modificar o substantivo, juntando-se a ele, quando é chamado de adjetivo atributivo. Ou pode modificá-lo através de um verbo, como adjetivo predicativo. Em homem gordo, mulher elegante, o adjetivo é 
atributivo. Em o homem é gordo, a mulher parece elegante, o adjetivo é predicativo.

Apesar de a Nomenclatura Gramatical Brasileira registrar o pronome adjetivo, chama ao nome adjetivo simplesmente de adjetivo, deixando implícito que $\mathrm{o}$ adjetivo pode ser nome e pronome, visto que, tanto o nome adjetivo quanto o pronome adjetivo indicam qualidades ou propriedades dos seres, como esclarece Celso Pedro Luft (1972, s.v.).

Há certo grupo de adjetivos que indicam a origem de pessoas ou coisas, que são os adjetivos pátrios ou gentílicos, como: dom-cavatiense (Dom CavatiMG), mineiro (Minas Gerais), nordestino (Nordeste), brasileiro (Brasil), português (Portugal), europeu (Europa) etc. Alguns desses gentílicos possuem forma especial quando primeiro membro de uma composição, como é o caso de luso (de Portugal), em luso-brasileiro; hispano (de Espanha), em hispanoárabe; ítalo (de Itália), em ítalo-belga, franco (de França), em franco-suíço etc.

Certos adjetivos possuem também força verbal, tais como os particípios presente, passado ou futuro, também conhecidos como adjetivos verbais. Em português, não há particípios futuros na função verbal, e os particípios presentes se converteram em meros adjetivos ou substantivos. Entre os particípios passados, nem sempre é fácil distinguir quais são puros adjetivos. 0 adjetivo pode situar-se na categoria de nome (que é o adjetivo qualificativo) ou de pronome (que é o adjetivo determinativo), de modo que belo é um nome adjetivo e este é um pronome adjetivo.

O adjetivo é uma palavra variável e apresenta flexão de gênero (masculino e feminino), número (singular e plural) e grau (comparativo e superlativo) para concordar com o substantivo a que determina. Em português, o grau não se expressa por meio de flexão, como foi no latim.

Modificando o substantivo, o adjetivo concorda com ele em gênero e número, podendo antecedê-lo ou sucedê-lo. Se o adjetivo tiver valor meramente descritivo, deve ser posposto ao substantivo, como em livro verde, química orgânica, lei penal etc., exprimindo divisões e subdivisões de um conceito ou caracterizando simplesmente um ser segundo alguma qualidade que objetivamente lhe pertence. 
Quando, porém, o adjetivo possui um matiz subjetivo e adquire valor poético ou sugestivo, tende a ser anteposto ao substantivo, como em: verdes mares, terrível notícia, suave milagre, grandioso espetáculo etc. Em geral, a antecipação ou posposição do substantivo lhe modifica a significado como nos seguintes exemplos: homem pobre, pobre homem; grande cidade, cidade grande; certo amigo, amigo certo. Isto dá à língua portuguesa maior riqueza estilística, o que não é possível, por exemplo, com o inglês.

Certos adjetivos como alto, baixo, certo, errado, caro e barato podem ser usados como advérbios, em frases como falar alto, dizer baixo, andar certo, proceder errado, custar caro e vender barato. Neste caso, às vezes, sofrem flexão por atração, mesmo como advérbios.

Também é usual o emprego de adjetivos como advérbios de modo desprovidos do sufixo -mente. Nesse caso, é possível interpretá-lo como adjunto adverbial ou como anexo predicativo. Assim, na frase: "A neve caía, contínua e silenciosa", pode-se dar a contínua e silenciosa o valor de adjetivo ou de advérbio (continuamente e silenciosamente). O fato, aliás, se verifica igualmente em outras línguas românicas, conforme já havia observado Harri Meier (1974):

As línguas românicas distinguem um duplo emprego dos qualificativos: o emprego como adjetivo morfologicamente alterável e concordante com o nome ou pronome ao qual se liga, e o emprego como advérbio inalterável. (HARRI MEIER, 1974, p. 61)

As flexões dos adjetivos da língua portuguesa derivam das correspondentes flexões do latim, onde se distribuíam em duas classes: a primeira, com o acusativo singular em -um, -am, e -um, e os da segunda com acusativo em -em. O gênero neutro desapareceu, sendo incorporado frequentemente, ao masculino, comas duas terminações para os a primeira classe (-um, -am) e uma para os da segunda (-em). Com a queda do $-m$ final, tivemos as terminações $-u$, -a (depois $-o,-a$ ) para os primeiros, e -e, para os segundos, incluindo-se os casos em que a vogal caiu, depois de consoantes como r, I, s e z.

A consequência em português foi a seguinte: 1) adjetivos biformes em -0, -a, provenientes dos adjetivos de primeira classe latinos (tipo caro/cara, 
alto/alta, negro/negra etc.); 2) adjetivos uniformes em -e ou consoante, originários dos adjetivos de segunda classe latinos (tipo triste, forte, fácil, feliz etc.)

O - $s$ do plural dos adjetivos provém do $-s$ final do acusativo latino, cujos adjetivos da primeira classe faziam o plural em -os e -as, e os da segunda, em -es.

\subsection{Advérbio}

Advérbio é a palavra que modifica a significação do verbo, assim como o adjetivo modifica a significação do substantivo, sendo que os advérbios de intensidade podem modificar também o adjetivo ou outro advérbio. Neste caso, corresponde mais precisamente aos antigos morfemas destinados a exprimir gradação do que a palavras nocionais.

A conhecida definição de que advérbio é a palavra que pode modificar a significação do verbo, do adjetivo ou de outro advérbio é atribuída a Giulio Cesare Escalígero (1484-1558), apesar de poder modificar também todo o conteúdo de uma frase, como em "Dificilmente, terás outra oportunidade igual", como observa Celso Pedro Luft (1972, s.v.).

Os advérbios podem ocorrer numa frase simplesmente enunciativa, ou encabeçar uma frase interrogativa, quando se classificam como advérbios interrogativos (de tempo: quando?, de lugar: onde?, de modo: como? e de quantidade: quanto?).

Os advérbios modificam o verbo na sua significação vocabular ou 0 sentido da oração, ou the acrescentam uma circunstância. Daí a divisão em modificativos e circunstanciais, pelo que se vê que não pode ser definido exclusivamente como "palavra de circunstância", sendo que os advérbios modificativos ainda se subdividem em advérbios de modo (ou qualidade), que representam para a ação (verbo) aquilo que o adjetivo representa para o ser (substantivo), e advérbios de intensidade (ou quantidade). É por isso que um adjetivo se transforma facilmente em advérbio de modo. 
Como os adjetivos de que derivam, os advérbios de modo podem sofrer gradação, como se pode ver em lindamente (lindo) > mais lindamente (mais lindo), lindissimamente (lindíssimo), assim como bem, mal, certo, errado, assim, direito, adrede, acinte etc.

Os advérbios de intensidade (muito, pouco, mais, menos, assaz, bastante, algo, meio, tão, tanto, quão, quanto etc.) estão muito próximos dos pronomes indefinidos quantitativos, mas existem advérbios de intensidade correlativos, como "tanto... quanto" na frase "Estuda tanto, quanto o irmão".

Alguns advérbios de intensidade também são passíveis de gradação, como: muito (positivo): mais (comparativo) e muitíssimo (superlativo); pouco (positivo): menos (comparativo) e pouquíssimo (superlativo).

Dividem-se os advérbios modificativos de frase em de afirmação (sim, certo, certamente, sem dúvida etc.), de negação (não, nada, absolutamente, de forma alguma etc.) e de dúvida (talvez, acaso, quiçá, porventura, com certeza).

Os advérbios circunstanciais são os de tempo (hoje, amanhã, ontem, anteontem, agora, já, logo, antes, depois, cedo, tarde, imediatamente etc.) e lugar (aqui, aí, ali, lá, acolá, acima, abaixo, arriba, longe, perto, atrás, dentro, fora etc.), alguns dos quais são passíveis de gradação, como: mais perto, muito longe, mais cedo, muito tarde etc.

Os advérbios pronominais - hoje (neste dia), agora (nesta hora), então (naquela época), entre outros - são advérbios circunstanciais que equivalem a um substantivo determinado por um demonstrativo e regido de preposição. Por terem natureza de advérbio e de pronome, podem ser regidos de preposições, como em "as modas de então", "a mocidade de hoje" etc.

Certos autores ainda falam em advérbios de ordem (primeiro, depois, antes, na frente...) e de frequência (diariamente, frequentemente, às vezes, sempre, nunca...), que devem ser incluídos, respectivamente, entre os de lugar e os de tempo.

Alguns advérbios aparecem com terminação de diminutivo como formas afetivas de superlativo. Exemplos: pertinho, cedinho, agorinha.

Como palavra invariável que modifica: o verbo, um adjetivo, outro advérbio ou toda uma frase, ele não pode modificar um substantivo, que é 
função do adjetivo. As palavras que indicam inclusão e exclusão não estão classificadas como advérbios na Nomenclatura Gramatical Brasileira.

O advérbio que modifica o adjetivo ou outro advérbio faz a mesma função que o morfema de grau em outras línguas. Por exemplo: mais alto (latim altior), muito alto (latim altissimus).

Exemplo de advérbio modificando toda uma frase: "Infelizmente, não pudemos atender a todos os candidatos".

A forma gerundial do verbo, quando empregada sem complemento, desempenha, na análise sintática, a função de adjunto adverbial de modo, sem necessidade de se apelar para a oração reduzida. É o que se dá no conhecido exemplo camoniano: "Cantando espalharei por toda a parte".

Quando, numa frase, concorrem vários advérbios em -mente, é de praxe, para se aliviar o teor gramatical da expressão, só ajuntar tal sufixo ao último advérbio. Exemplo: "A monja caminhava triste e silenciosamente". A insistência no sufixo traduz intuito de ênfase. Exemplo: "Cumpria os seus deveres alegremente, fielmente, religiosamente".

O comparativo dos advérbios bem e mal é, respectivamente, melhor e pior. Antes de particípios passados, porém, pode-se usar a forma analítica mais bem e mais mal. Exemplos: As casas mais mal construídas serão pintadas. Esses problemas precisam ser mais bem estruturados.

O advérbio talvez, anteposto ao verbo, leva-o ao subjuntivo; posposto, leva-o ao indicativo. Exemplos: Talvez eu consiga. Eu conseguirei, talvez, o lugar.

\subsection{Artigo}

Segundo Sílvio Edmundo Elia (1962, s.v.), artigo é a partícula que, em português, se antepõe ao substantivo para mais facilmente permitir o seu relacionamento com as outras palavras da frase. Do ponto de vista da forma, concorda com o substantivo, deixando claro qual é seu gênero e número, principalmente quando se trata do gênero (imanente no substantivo), que não é expresso por flexão, manifestando sua determinação (feita pelos artigos em 
definidos: o, a, os, as) ou indeterminação (feita pelos artigos indefinidos: um, uma, uns, umas).

Apesar de existir o artigo partitivo, em português, a função partitiva é desempenhada pela preposição de, como se pode ver em: provar do vinho, beber da água, comer do bolo etc.

O artigo definido serve para particularizar determinado indivíduo dentre vários da mesma espécie. Exemplo: Traga-me o vinho (trata-se de um vinho determinado, conhecido pela pessoa a quem foi dirigida a ordem), E o indefinido designa indiferentemente qualquer indivíduo de determinada espécie de seres. Exemplo: Traga-me um vinho (não se trata de um vinho já conhecido da pessoa a quem foi dirigida a ordem; a pessoa deve saber o que é vinho, isto é, conhecer a espécie do objeto em causa e trazer simplesmente qualquer um deles).

Quando não se quer fazer referência a um dos indivíduos da espécie, nem determinada nem indeterminadamente, a rigor não se deveria usar artigo de espécie alguma. É o que se dá muitas vezes, como no famoso Um Apólogo, de Machado de Assis: Agulha não tem cabeça, isto é, todas as agulhas e não esta ou aquela, determinada ou indeterminadamente. Em ditos proverbiais e sentenciosos, também o normal é a ausência de artigo. Exemplos: cachorro que late não morde; quem não tem cão caça com gato. $\mathrm{O}$ artigo definido pode indicar também toda uma classe ou espécie, como em: A mulher é mais frágil que o homem. O homem é mortal.

O uso do artigo definido com nomes próprios de pessoas indica tratar-se de pessoa muito conhecida dos ouvintes. Exemplo: "Ah! o senhor é que é o Pestana?" (Machado de Assis)

Nos cognomes e alcunhas de pessoas célebres, usa-se o artigo definido: Joana, a Louca; Filipe, o Belo; Carlos, o Calvo, apesar de haver exceções.

Igualmente são precedidos de artigo os nomes próprios personativos usados como protótipos de uma classe de indivíduos. É o que se dá em: Os Ruis são patrimônio de uma pátria. Os Homeros cantaram a glória de seus povos, por exemplo. 
Se designarmos uma obra pelo nome do autor, este deverá levar o artigo. Exemplos: Esta etimologia está no Nascentes, Vou consultar o Morais.

Os nomes de continentes, vastas regiões de terra, países e nações são, geralmente, empregados com artigos (a América, a Europa, o Brasil, a França, a Irlanda), assim como a maioria dos nomes de cidades, mas podem dispensar o artigo, se estiverem precedidos de preposição, como em reis de Inglaterra, grandes de Espanha, fio de Escócia.

Em relação ao artigo indefinido, deve-se observar que é mais elegante evitá-lo, principalmente quando vem modificado por um adjetivo. Assim, “Trazia sobre os ombros belo xale de seda" é preferível a "Trazia sobre os ombros um belo xale de seda".

\subsection{Composição}

Segundo Sílvio Edmundo Elia (1962, s.v.), composição é o processo de formação de palavras pelo qual se juntam dois ou mais semantemas, que podem ser dois radicais, ou um prefixo e um radical.

No caso de dois radicais, temos um composto por associação (por justaposição, por aglutinação e por locução); no caso de prefixo e radical, um composto por prefixação.

Nos compostos por justaposição, juntam-se duas palavras que atenuam a sua significação própria para criar um sentido novo, como em couve-flor e pé de meia.

Nos compostos por aglutinação, os dois elementos se fundem tão intimamente, que o primeiro sofre alteração na sua parte final, como em planalto, pernalta, aguardente, bancarrota etc.

Nos compostos por locução, há uma preposição intermediando os termos. Exemplos: fogão a gás, máquina de costura, para que, a fim de que, água-decolônia, pé de moleque, olho-de-boi, pão de ló etc. Segundo Celso Pedro Luft (1972, s.v.), todas as locuções são casos de justaposição, e a ortografia manda escrevê-las sem o hífen, exceto os termos de zoologia e botânica. No entanto, 
mesmo depois do Acordo Ortográfico da Língua Portuguesa de 1990, ainda não está clara a distinção entre locução e palavra composta.

Os compostos por prefixação são da fórmula prefixo + radical. Exemplos: prejulgar, refazer, injustiça, simpatia, perímetro etc. Há autores que incluem a prefixação no processo de derivação e não no da composição, subdividindo a derivação em prefixal e sufixal. Preferimos a doutrina que expusemos, por ser o prefixo um semantema (embora auxiliar) e não um morfema. Observemos ainda que os limites entre a prefixação e a composição stricto sensu nem sempre são muito nítidos. Entreabrir, por exemplo, será uma palavra composta por justaposição ou por prefixação?

\subsection{Conjunção}

Conjunção é o conectivo de orações e, mais restritamente, de palavras ou expressões vocabulares.

Há duas classes de conjunções: as coordenativas e as subordinativas. As conjunções coordenativas ligam duas orações ou dois termos da oração sintaticamente independentes. Quando ligam termos da oração, temos a relação sintática dita "composição" (sujeitos compostos, objetos compostos, adjuntos compostos...). É o caso de, por exemplo: Pedro e Paulo são irmãos (sujeito composto), Comprei um lápis e um caderno (objeto composto), Ponhao na caixa ou na gaveta (adjunto adverbial composto).

As conjunções subordinativas relacionam apenas orações, entre as quais criam um estado de dependência. A oração dependente se chama, então, subordinada, e aquela da qual depende é a principal. A oração principal pode estar subordinada a uma terceira, como em "Pedro disse que queria saber onde puseste o livro", em que a oração "que queria saber" é principal em relação à oração "onde puseste o livro", mas é subordinada à oração "Pedro disse”. A oração principal que não está subordinada a nenhuma outra é a principal em sentido absoluto.

São as seguintes as subdivisões das conjunções: 
Coordenativas: a) aditivas (e, nem, não só... mas também); b) adversativas (mas, porém, contudo, todavia, entretanto, não obstante), c) alternativas (ou, ou... ou, ora... ora, quer... quer, seja... seja, já... já), d) conclusivas (logo, pois, portanto, por conseguinte) e e) explicativas (pois, que, porque);

Subordinativas: a) causais (que, porque, porquanto, como, já que, dado que, por isso que, visto que, visto como, uma vez que), b) concessivas (embora, conquanto, ainda que, se bem que, mesmo que, posto que), c) condicionais (se, contanto que, senão, uma vez que, desde que, sem que), d) consecutiva (que), e) comparativas (que, do que, como, quanto), f) conformativas (como, conforme, consoante, segundo), g) finais (que, para que, a fim de que, porque), h) integrantes (que e se), i) proporcionais (ao passo que, à medida que, à proporção que, enquanto) e j) temporais (quando, assim que, logo que, tanto que, antes que, depois que, apenas, mal).

Há dois processos gerais de composição do período: coordenação (com orações situadas no mesmo plano lógico-sintático) e subordinação (com orações situadas em planos hierarquicamente diferentes), além da correlação, que não se justifica, pois, embora tenha caracteres sintáticos próprios, do ponto de vista do valor lógico, não se distingue da coordenação nem da subordinação.

No caso de não só... mas também, por exemplo, há correlação coordenativa; no de tanto... que, há correlação subordinativa. Ademais, a correlação subordinativa não se limita aos tipos consecutivo e comparativo, como geralmente se faz. Na concessão e na condição há também uma correlação, ainda que mais atenuada, como já observou Joaquim Matoso Câmara Jr.

As conjunções "que", "pois" e "porque" podem ter valor coordenativo ou subordinativo. No primeiro caso, são explicativas; no segundo caso, são causais. As explicativas não dão a causa determinante do fato, mas procuram acrescentar uma explicação após ter sido completada a enunciação de um acontecimento. Em exemplo como o seguinte, apresentado por João Ribeiro (1906, s.v.) - "É primavera, pois as árvores estão cobertas de flores", pode se 
dizer que a oração encabeçada por pois não é causal no sentido próprio do termo, porquanto não é o desabrochar das flores que produz a primavera. Trata-se de mera relação de concomitância em que a segunda oração procura dar uma razão de ser para a afirmativa, não para o fato como fenômeno da natureza.

\subsection{Derivação}

Segundo Sílvio Edmundo Elia (1962, s.v.), derivação é o processo de formação de palavra por meio de sufixo, que pode ser acrescentado diretamente à raiz da palavra (formação primária. Exemplo: amor - o sufixo -or foi acrescentado diretamente à raiz $a m$-) ou à própria palavra (formação secundária. Exemplo: amoroso - o sufixo -oso foi acrescentado à própria palavra amor).

Alguns autores dão à derivação sentido mais amplo, incluindo qualquer formação nova por meio de afixo. Outros, no entanto, consideram a derivação prefixal como processo de composição, porque muitos prefixos são (ou foram) palavras autônomas (preposições ou advérbios).

Manuel Said Ali distinguia entre derivação prefixal e sufixal, tendo bastante seguidores no Brasil. Sílvio Edmundo Elia (1962, s.v.), no entanto, prefere a colocação clássica do tema, que põe a prefixação como processo de composição e a sufixação como de derivação, considerando que o sufixo tem função gramaticalizadora, é um morfema, situa a palavra numa das grandes categorias léxicas (nome, verbo, advérbio), ao passo que o prefixo apenas ajunta ao radical uma ideia acessória, precisando-Ihe um pouco mais o sentido geral que lhe é próprio, como semantema auxiliar. Assim, do adjetivo justo pode-se tirar, por prefixação, o composto injusto, também adjetivo; por outro lado, com o sufixo -iça, faremos a palavra derivada justiça, que não é adjetivo, mas substantivo.

Normalmente, a palavra derivada se forma pelo acréscimo de um sufixo. Às vezes, porém, se dá o contrário. Reserva-se para este último caso o nome de derivação regressiva, em oposição ao processo normal, chamado derivação 
progressiva. Um exemplo seria a palavra aço, que deriva da palavra aceiro. Caso mais comum de regressivos é constituído pelos chamados substantivos deverbais ou pós-verbais, que são substantivos que se derivam de verbos pela supressão de elementos mórficos. Honra, por exemplo, regressivo de honrar.

Com o nome de derivação imprópria se alude ao processo que consiste em criar uma palavra nova sem acréscimo nem supressão de sufixo; usa-se do outro recurso gramatical (mudança de categoria, de gênero etc.). Exemplos: porque (conjunção) e porque (substantivo), a cabeça (parte do corpo, significação primitiva), o cabeça (chefete, significação derivada). Derivação imprópria é parte da semântica e não da morfologia.

Existe ainda um outro processo de derivação chamado parassintético. Consiste na formação de palavras simultaneamente por composição e por derivação. Destarte, o parassintético pode obedecer às seguintes fórmulas: a) prefixo + radical + sufixo. Exemplo: envelhecer $(\mathrm{en}$, prefixo + velh, radical + ecer, sufixo); b) radical + radical + sufixo. Exemplo: sanguissedento (sangu, radical + sed, radical + ento, sufixo).

Para que haja formação parassintética, é necessário que os dois processos sejam empregados simultaneamente. Uma palavra como injustiça, por exemplo, não é parassintética, embora tenha prefixo e sufixo. É que tal palavra ou foi formada de injusto (nesse caso, é derivada), ou foi formada de justiça (nesse caso, é composta).

\subsection{Flexão}

Flexão é a variação que as palavras sofrem para concordarem com outras a que estão sintaticamente relacionadas: "variações que podem sofrer as palavras para expressar suas funções - o gênero, o número, a pessoa, mediante a afixação de desinências". (MACEDO, 1979, s.v.)

Segundo Sílvio Edmundo Elia (1962, s.v.), flexão é a alteração que as palavras ditas variáveis sofrem na sua parte final para indicar alguns dos acidentes gramaticais (acidentes que Walmírio de Macedo chamou de funções). 
Os acidentes gramaticais são, em português: o gênero, o número e o grau (para os nomes); a pessoa, o número, o tempo e o modo (para os verbos), embora outras línguas tenham acidentes gramaticais, como o latim, que tem as flexões de caso e de voz.

Em português, o tipo normal de flexão é o da chamada flexão temática em que se acrescentam sufixalmente alguns elementos denominados "desinências" ao tema.

A ausência de desinência numa oposição constante é tão característica quanto a sua presença; chama-se, então, desinência zero. É o que se dá em português na oposição singular-plural, tipo rosa-rosas, em que, à desinência -s, de plural se opõe, no singular, a desinência zero.

Celso Pedro Luft (1972, s.v.) lembra que a flexão se faz por meio de desinências ou sufixos flexionais, podendo ser nominais (de gênero e de número) ou verbais (modo-temporais e número-pessoais), externas (campos, belas, estávamos) ou internas (ele/ela, foi/fui, fiz/fez, qua/quer/quaisquer), sendo que a flexão interna ocorre quase sempre como marca distintiva complementar.

Em português, segundo Sílvio Edmundo Elia (1962, s.v.), é rara a flexão interna, que só existe acidentalmente: avô (masculino), avó (feminino); fazes (presente), fizeste (pretérito). A flexão interna pode, entretanto, como um caráter secundário, acompanhar a flexão externa. É o que se dá, em virtude de metafonia, em certos femininos e plurais com a vogal o. Exemplos: formosoformosa, ovo-ovos (alternância ô-ó)

\subsection{Interjeição}

Classe de palavras que manifestam de maneira predominante a afetividade da pessoa que fala.

Pela sua própria natureza, as interjeições não podem ter função representativa. Dividem-se em exclamativas ( que exprimem alegria, dor, entusiasmo, revolta, pasmo etc., tais como: Oh! Ah! Chi! Ora! Hurra! Arre! Irra! Ai! Ui! Hum! Oxalá! Ué! etc.) e apelativas - que surgem no discurso dialogado e 
podem pretender levar à ação, quer uma pessoa, quer um animal, tais como: Psit! Psiu! Bit! bit! Ei! Bem! Olá! etc.

Celso Pedro Luft (1972, s.v.) diz que interjeição é o som, palavra ou expressão que exprime emoções súbitas ou ideias imperfeitamente estruturadas. Citando Joaquim Matoso Câmara Júnior, ele diz que a interjeição é "uma verdadeira palavra-frase [às vezes, apenas 'som-frase'] pela qual o sujeito falante, impregnado de emoção, procura exprimir seu estado psíquico, num movimento súbito, em vez de se expressar por uma frase logicamente organizada" (CÂMARA JR, 1968, apud LUFT, 1972, s.v.).

Além das interjeições, existem as palavras interjectivas e as locuções interjectivas. Palavras interjectivas são palavras pertencentes a outras categorias léxicas, mas que, em virtude do emprego frequente em situações afetivas, acabaram por impregnar-se de uma carga emotiva que as fez adquirir caráter interjectivo. Exemplos: Passa! Toca! Cruzes! Adeus! Credo" Bravo! Fora! Viva! Diacho! Locuções interjectivas são duas ou mais palavras que possuem, em conjunto, valor interjectivo. Exemplos: Ora, bolas! Com mil bombas! Bom dia! Até amanhã! Deus do céu! etc.

"As interjeições são inumeráveis, se atendermos ao grande número de vozes usadas pelos mercadores e vendilhões ambulantes e as vozes empregadas para com os animais... além de gritos e articulações e outros ruídos que não são representáveis pela escrita" (RIBEIRO, 1906, s.v.).

As interjeições são verdadeiras frases condensadas pela intensidade da emoção que as cria, o que impede ao sujeito falante uma expressão sintaticamente estruturada. Da interjeição se deve (de acordo com Eric Buyssens, 1978) distinguir a rese, que vem a ser o membro de uma oração destacado, pela força emotiva, da situação que a gerou. Exemplos: Admirável! Belo! Fogo! Ótimo! Patife! etc. Às vezes, torna-se difícil distinguir entre rese e palavra interjectiva. Exemplo: Rua!

As frases são, portanto, de três tipos: oração, rese e interjeição. Desses três tipos, somente a oração pode ser usada em discurso indireto, porque, pelo seu caráter lógico-representativo, o discurso indireto não admite o tom afetivo. 
Por outras palavras, nem toda frase é puramente representativa ou intelectiva; há também as frases emotivas ou afetivas.

Na gramática grega, a interjeição não é uma classe de palavras, mas está incluída entre os advérbios, mas os romanos a constituíram como uma parte da oração. O nome interjectio, significando "lançado entre", mostra que a interjeição não se prende estruturalmente à frase em que ocorre.

\subsection{Lexiologia}

Lexiologia, segundo Sílvio Edmundo Elia (1962, s.v.), é o estudo do vocabulário de uma língua, não como conjunto de palavras isoladas que se somam como unidades dispersas, mas como séries de palavras que mantêm entre si relações no plano da língua, as quais permitem generalizações cientificamente válidas. A semântica, no seu aspecto descritivo, pertence à lexicologia, e as observações sobre o caráter ruralista e concreto da língua latina, por exemplo, são conclusões de ordem lexicológica. Por isto, frequentemente, termo lexicologia é usado como sinônimo de lexiologia.

Segundo Celso Pedro Luft (1972, s.v.), lexiologia é o tratado ou estudo do léxico de uma língua, ocupando-se das palavras quanto a sua estrutura e aos processos de afixação (derivação) e composição. Mas alerta que, para alguns gramáticos, a lexiologia abrange também o estudo das flexões.

\subsection{Morfema}

Segundo Sílvio Edmundo Elia (1962, s.v.), a palavra "morfema" tem um sentido na escola francesa de linguística e outro na escola norte-americana.

Para a escola francesa, morfema se opõe a semantema. Numa frase como "o cavalo corre", temos as ideias de cavalo (um animal) e de correr (um ato). Mas o significado da frase não se esgota aí: cavalo é masculino e singular, corre está no presente do indicativo, a frase é afirmativa etc. Há, pois, nessa frase, duas ordens de elementos significativos, pois, segundo Joseph Vendryès (1875-1960): os semantemas, que exprimem ideias de 
representação, e os morfemas, que denotam as relações entre essas ideias. Em jumento, por exemplo, jument- é um semantema, pois contém um conceito nocional (a de ser um ser vivo, vertebrado, quadrúpede, herbívoro etc.), ao passo que -o é um morfema próprio de um nome no gênero masculino. Em resumo, o semantema exprime ideias e o morfema, relações gramaticais.

Já para a escola norte-americana, morfema se opõe a fonema. Numa língua, segundo Henry Allan Gleason (1882-1975), ou há elementos não significativos (fonemas), ou elementos significativos (morfemas). Fonema é o menor elemento de caráter distintivo que pode ser isolado no plano da expressão. Morfema é a menor unidade no plano da expressão que pode ser relacionada diretamente com qualquer parte no plano do conteúdo. Diferentemente da a escola francesa, para a qual, os semantemas são os radicais (ou temas primários, secundários etc.) e os morfemas são os afixos (prefixos, infixos e sufixos) e as desinências.

Em português, os prefixos não funcionam como morfemas (no sentido da escola francesa), e, sim, como semantemas auxiliares, mas, para a escola norte-americana, no entanto, raízes, radicais, afixos, desinências, tudo são morfemas.

Note-se que a noção de morfema não está ligada diretamente à de forma (no sentido de morfologia, por exemplo). Há morfemas de caráter fonológico, que consistem não em oposição de fonemas, mas de prosodemas, que são as menores unidades prosódicas de uma língua. Exemplo: amara (pretérito maisque-perfeito do indicativo) amará (futuro do presente). Há também os morfemas de natureza sintática. Exemplo: Josefa ama Pedro. O sujeito Josefa não se identifica por nenhum índice formal, mas simplesmente pela posição (ordem) dos termos na oração. Se invertermos a ordem, o sujeito passa a ser Pedro: Pedro ama Josefa.

\subsection{Numeral}

Classe de palavras que designa o número certo de objetos, que podem ser: cardinais, ordinais, fracionários e multiplicativos. 
Os numerais cardinais designam a série natural dos números inteiros. São os numerais propriamente ditos, dos quais os outros são derivados. Exemplos: um, dois, três, vinte, mil, dois mil, três mil e quinhentos etc. Funcionam quase sempre como adjetivos (oito rodas, dez dedos etc.), mas também podem ter valor de substantivo. Exemplo: dois e dois são quatro; 0 triplo de três são nove etc. Zero é um numeral substantivo e, por isso, pode ter plural. Exemplos: Faltam três zeros à esquerda. Também nove, na expressão prova dos noves. Zero é adjetivo quando acompanhado de substantivo do plural. Exemplo: Zero horas.

Os ordinais indicam a posição dos objetos numa série limitada. Exemplos: primeiro, segundo, décimo, vigésimo etc.

Os fracionários indicam o número de partes iguais em que foi dividida a unidade: meio, terço, quarto, décimo, onze avos etc.

Os multiplicativos indicam o número de vezes que se tomou a unidade: duplo, triplo, quádruplo etc.

Ainda há um tipo de numeral de que é o numeral dual, representado pela palavra ambos, simples ou reforçada. Exemplo: Carlos e Tânia, ambos são digitadores. Ambos os dois, no entanto, estão desempregados.

\subsection{Preposição}

Walmírio de Macedo (1979, s.v.) ensina que preposição e a "palavra que subordina um termo a outro", complementado por Tassilo Orpheu Spalding (1971, s.v.), que esclarece mais: "é palavra intervocabular que indica a relação sintática entre dois termos", exemplificando com a frase "Partiu para Paris". Portanto, sintetizando com Celso Pedro Luft (1972, s.v.), pode-se dizer que preposição é palavra invariável que relaciona dois termos, explicando ou complementando o sentido do primeiro (termo antecedente) pelo segundo (termo consequente).

Trata-se de um termo que tem as seguintes características: a) é um vocábulo gramaticalmente invariável; b) estabelece relação de subordinação 
entre dois termos; c) rege normalmente um termo de natureza substantiva e d) precede o termo regido (motivo pelo qual se chama preposição).

As preposições podem ser, segundo Tassilo Orpheu Spalding (1971, s.v.), próprios ou essenciais, palavras preposicionais e expressões preposicionais.

a) próprias ou essenciais, isto é, palavras de natureza preposicional: $a$, ante, após, até, com, contra, de, desde, em, entre, para, por, sem, sob, sobre. Exemplos: "Veio a cavalo", "Postou-se ante o soberano", "Após a ceia", "Chegou até nós", "Voltado contra o poente", "Venho de casa", "Desde a manhã até à noite", "Traduziu em vulgar", "Sob o domínio do Império", "Prevaleceu sobre todos" etc. Os compiladores insistem em catalogar trás como preposição. Atualmente, tal praxe não se justifica.

b) palavras preposicionais, isto é, usadas invariavelmente como preposições: exceto, salvo, visto, tocante, segundo, durante, mediante, conforme, feito, tirante etc.

c) expressões preposicionais, isto é, um grupo de palavras que, sempre terminado por preposição própria ou essencial, é integralmente equivalente a uma preposição: à roda de, acerca de, defronte de, perto de, junto a, de concerto com, de acordo com, para com, atrás de etc.

É interessante lembrar também, como observa Celso Pedro Luft (1972, s.v.), que as preposições acidentais não obrigam os pronomes pessoais a assumir a forma dos pronomes oblíquos. Exemplo: Todos, menos eu (menos tu etc.). Para alguns autores, tais palavras não são preposições, mas palavras denotativas ${ }^{3}$.

A preposição indica a relação entre o antecedente e o consequente. Às vezes, duas preposições próprias ou essenciais concorrem sintaticamente, regendo o mesmo consequente: "Foi injusto para com o velho", "O árdego corcel galopava por entre pedras" etc. Normalmente, a conjunção coordenativa aditiva $e$ funciona como preposição: "Entre o malho $e$ a bigorna".

Joaquim Matoso Câmara Júnior (1968, s.v.) ainda acrescenta que as proposições são vocábulos que servem de morfemas de relação para

\footnotetext{
${ }^{3}$ Segundo a $N G B$, "Certas palavras, por não se poderem enquadrar entro os advérbios, terão classificação à parte. São palavras que denotam exclusão, inclusão, situação, designação, retificação, realce, afetividade etc.".
} 
subordinar um substantivo como adjunto ou complemento um adjetivo ou a outro substantivo (Ex.: carente de afeto, livro de pedro, medo de assombração) ou a um verbo (Ex.: fugiu de mim, iremos a São Paulo). Esse processo de subordinação tem o nome de regência. As preposições acumulam essa função com noções categóricas de posse, de posição, de direção, de proveniência etc.

\subsection{Pronome}

Walmírio de Macedo (1979, s.v.) diz que pronome é palavra que denota o ente ou a ele se refere, considerando-o apenas como pessoa do discurso, e que os pronomes podem ser: pessoais, possessivos, demonstrativos, indefinidos, relativos e interrogativos ${ }^{4}$, enquanto Tassillo Orpheu Spalding (1971, s.v.) já havia escrito que pronome é palavra que se emprega para substituir os nomes, para se evitar a sua repetição, definindo e exemplificando cada um deles.

É por isto que há uma classificação inicial dos pronomes como pronome substantivo (o que denota o ser) e pronome adjetivo (o que a ele se refere), conforme se vê na frase: "Isto aconteceu em outros tempos" que corresponde a "O fato aconteceu em tempos remotos". Assim, pode-se concluir com Celso Pedro Luft (1972, s.v.), que pronome é um vocábulo gramatical, de significação interna, que contrasta com o nome e com o verbo que são vocábulos lexicais, de significação externa.

\subsection{Substantivo}

Joaquim Matoso Câmara Júnior (1968, s.v.) define substantivo como todo nome ou pronome que designa um ser, caracterizando-se na frase pela possibilidade de funcionar como sujeito ou objeto.

\footnotetext{
${ }^{4}$ Celso Pedro Luft (1972, s.v.) esclarece que os pronomes interrogativos e os relativos são espécies de pronomes indefinidos.
} 
Por serem imanentemente masculinos ou femininos, os determinantes do substantivo (adjetivos, artigos, numerais e pronomes) têm de concordar com ele, tanto em gênero quanto em número.

Quanto à denotação, o substantivo pode ser próprio ou comum, conforme evoque um ser particular (José, Brasil) ou um conjunto constante de propriedades essenciais (homem, país).

O nome substantivo, ou substantivo simplesmente, por outro lado, como nos ensina Celso Pedro Luft (1972, s.v.), contrasta na significação com o pronome substantivo: o nome substantivo tem significação externa, designando o ser de maneira absoluta, implicando conceito ou noção, ao passo que o pronome substantivo só tem significação interna, denotando o ser de maneira relativa, contextual, gramatical, referindo-se às pessoas gramaticais.

Além disso, pode-se entender, ainda conforme Celso Pedro Luft (1972, s.v.), que há substantivos essenciais (os que normalmente funcionam como substantivos: homem, mulher, criança, livro, colégio, escola etc.) e substantivos acidentais (os que eventualmente, por substantivação, funcionam como tais: 0 belo, o útil, o correr, o treze, um quê, um mas etc.).

\subsection{Verbo}

Celso Pedro Luft (1972, s.v.) diz que verbo é palavra variável que exprime um processo, apresentando uma ação (correr), um fenômeno (chover), um estado (ser) ou mudança de estado (tornar-se). Por isto, o verbo apresenta os seres no tempo. Isto é, dinamicamente, em contraste com o nome, que apresenta as realidades, estaticamente, no espaço.

Segundo Celso Pedro Luft (1972, s.v.), o que essencialmente caracteriza o verbo (palavra mestra da frase) é a ideia temporal: a ideia da duração ou do resultado de um processo (aspecto) e a ideia do momento de sua ocorrência (tempo).

Para David Crystal (1988, s.v.), verbo é o termo usado na classificação gramatical das palavras que indicam uma classe definida como palavras de "ação". Mas a definição formal de um verbo se refere a um elemento que 
mostra contrastes morfológicos de tempo, aspecto, voz, modo, pessoa e número, sendo que, funcionalmente, é o elemento que (sozinho ou junto com outros verbos) é utilizado como predicado mínimo de uma sentença, coocorrendo com o sujeito.

O Dicionário Gramatical de Cândido de Oliveira (1967, s.v.) relaciona uma série de verbetes para o verbo, definido como palavra que indica "fazer alguma cousa" ou "ser alguma cousa", podendo ser regular, irregular, anômalo, defectivo, abundante e auxiliar. Entre esses termos, muitos foram abolidos pela Nomenclatura Gramatical Brasileira, entre os quais lembra que existe verbo acurativo, biobjetivo, birreflexivo, bitransitivo, causativo, copulativo, depoente, determinativo, frequentativo, imitativo, impessoal, incoativo, irregular fraco, irregular forte, iterativo, neutro, nocional, pessoal, predicativo, pronominal, relacional, relativo, transitivo-predicativo, transobjetivo, transpredicativo, unipessoal e vicário.

Como nos lembra Celso Pedro Luft (1972, s.v.), provavelmente, é pelo fato de o verbo ser a palavra mestra da frase e núcleo da oração, que os latinos lhe deram o nome de verbum, isto é, a palavra.

\section{Considerações finais}

Naturalmente, muito do que está no verbete "morfologia", explícita ou implicitamente, não pode ser apresentado em um artigo.

Apesar de não ter conseguido eliminar algumas repetições, tentou-se uma síntese do que vai apresentado nesse verbete, nos principais dicionários de gramática e linguística em português, produzidos a partir de nossa realidade ou adaptados em traduções de outras línguas.

Para isto, os elementos claramente repetitivos foram eliminados ou sintetizados em nova redação, a partir dos autores citados, além de excluir sistematicamente os elementos rigorosamente diacrônicos ou históricos, com raríssimas exceções.

Os termos mais comuns e mais recorrentes relativos à morfologia foram registrados aqui, mas, para a realização de um trabalho mais abrangente sobre o verbete será importante relacionar outros termos ou expressões, como: 
absolutivo, acumulação nos elementos mórficos, acúmulo de preposições, acusativo, adjetivação de orações substantivas, adverbialização de adjetivos, afixação, afixo, aglutinação, alomorfe, artigo partitivo, aspecto verbal, aumentativo, auxiliares causativos, auxiliares sensitivos, cardinal, casos, categorias gramaticais, classe de palavra, classe verbal, classes linguísticas, condicional, conjugação de verbos, conjunção (integrante, aditiva, adversativa, alternativa, coordenada, subordinadas), coordenação, criação de palavras, dativo livre, Dêixis, derivação (prefixal, sufixal), desinência (nominal, verbal), deverbal, diminutivo, duração, feminino, flexão, flexionismo, forma (arrizotônica, arrizotônica), forma de tratamento, forma nominal do verbo, formação de palavras, formação deverbal, fracionário, futuro, gênero (do substantivo, do adjetivo), gerúndio, gradação do adjetivo, hibridismo, indicativo, infinitivo, infixo, intensificação, interfixo, justaposição, masculino, modalidade, modalização, modos do verbo, monema, morfema (aditivo, derivativo, flexional, modificativo, subtrativo, zero), mórfica, morfossintaxe, nominalização, número (do adjetivo, plural, singular), optativo, ordinal, particípio, passado, passiva, pessoa, plural, prefixo, presente, pretérito (imperfeito, mais-que-perfeito, perfeito), radical, raiz, C, sintagma, substantivação, sufixo, taxionomia, tema, tempo, vocábulo e voz (ativa, passiva, reflexiva), além de muitos outros, tanto arcaicos quanto neológicos, de uso amplo ou de uso restrito na gramaticologia.

Enfim, fica o agradecimento à coordenação deste número da revista pela oportunidade de apresentar este tema, prometendo-se um trabalho mais completo para o ano de 2018, quando se espera a conclusão da redação de um novo e mais completo Dicionário de Linguística e Gramática, na linha das pesquisas de terminologia científica, para o qual ainda se está relacionando o material na bibliografia específica disponível.

\section{Referências bibliográficas}

ALI, Manuel Said. Gramática histórica da língua portuguesa. 7. ed. melh. e aum. de Lexeologia e Formação de Palavras e Sintaxe do Português Histórico. Estabelecimento do texto, revisão, notas e índices pelo Prof. Maximiano de Carvalho e Silva. Rio de Janeiro: Acadêmica/Melhoramentos, 1971. 
BUYSSENS, Eric. Semiologia \& comunicação linguística. São Paulo: Cultrix, 1974.

CÂMARA JÚNIOR, Joaquim Matoso. Dicionário de filologia e gramática: referente à língua portuguesa. 3. ed. Rio de Janeiro: José Olympio, 1968.

CRYSTAL, David. Dicionário de linguística e fonética. Tradução e adaptação: Maria Carmelita Pádua Dias. Rio de Janeiro: Jorge Zahar, 1988.

DUBOIS, Jean et al. Dicionário de linguística. Direção e coordenação geral da tradução: Izidoro Blikstein. São Paulo: Cultrix, [1998]

ELIA, Sílvio Edmundo. "Dicionário gramatical português". In: __ et al. Dicionário gramática. Rio de Janeiro, Porto Alegre e São Paulo: Globo, 1962, p. 1-205.

LUFT, Celso Pedro. Dicionário gramatical da língua portuguesa. Porto Alegre: Globo, 1972.

MACEDO, Walmírio de Macedo. Dicionário de gramática. Rio de Janeiro: Ediouro, 1979.

MEIER, Harri. Ensaios de Filologia Românica. 3. ed. Rio de Janeiro: Grifo, 1974.

OLIVEIRA, Cândido de. Dicionário gramatical. São Paulo: F.T.D., 1967.

RIBEIRO, João. Dicionário gramatical. 3. ed. Rio de Janeiro: Francisco Alves, 1906.

SPALDING, Tassilo Orpheu. Dicionário brasileiro de gramática. São Paulo: Cultrix, 1971. 